\title{
OPEN Author Correction: Performance of a glucose-reactive enzyme-based biofuel cell system for biomedical applications
}

Won-Yong Jeon $\mathbb{D}$, Jung-Hwan Lee $\mathbb{D}$, Khandmaa Dashnyam, Young-Bong Choi, TaeHyun Kim, Hae-Hyoung Lee, Hae-Won Kim \& Hyug-Han Kim

Correction to: Scientific Reports https://doi.org/10.1038/s41598-019-47392-1, published online 26 July 2019

In the original version of this Article, there were errors in the Affiliations which were incorrectly listed as 'Department of Chemistry, College of Natural Science, East Lansing, USA,' 'Institute of Tissue Regeneration Engineering (ITREN), Chungnam, Republic of Korea.', 'Department of Nanobiomedical Science \& BK21 PLUS NBM Global Research Center for Regenerative Medicine, Cairo, Egypt.', 'UCL Eastman-Korea Dental Medicine Innovation Centre, Chungnam, Republic of Korea., and 'Department of Biomaterials Science, College of Dentistry, Dankook University, Chungnam, Cheonan, 31116, Republic of Korea., respectively.

The correct affiliations are listed below:

Affiliation 1

Department of Chemistry, College of Natural Science, Dankook University, Chungnam, Cheonan, 31116, Republic of Korea.

Affiliation 2

Institute of Tissue Regeneration Engineering (ITREN), Dankook University, Chungnam, Cheonan, 31116, Republic of Korea.

Affiliation 3

Department of Nanobiomedical Science \& BK21 PLUS NBM Global Research Center for Regenerative Medicine, Dankook University, Chungnam, Cheonan, 31116, Republic of Korea.

Affiliation 4

UCL Eastman-Korea Dental Medicine Innovation Centre, Dankook University, Chungnam, Cheonan, 31116, Republic of Korea.

\section{Affiliation 5}

Department of Biomaterials Science, College of Dentistry, Dankook University, Chungnam, Cheonan, 31116, Republic of Korea.

These errors have now been corrected in the PDF and HTML versions of the article and in the Supplementary Information. 
(c) (i) Open Access This article is licensed under a Creative Commons Attribution 4.0 International License, which permits use, sharing, adaptation, distribution and reproduction in any medium or format, as long as you give appropriate credit to the original author(s) and the source, provide a link to the Creative Commons license, and indicate if changes were made. The images or other third party material in this article are included in the article's Creative Commons license, unless indicated otherwise in a credit line to the material. If material is not included in the article's Creative Commons license and your intended use is not permitted by statutory regulation or exceeds the permitted use, you will need to obtain permission directly from the copyright holder. To view a copy of this license, visit http://creativecommons.org/licenses/by/4.0/.

(C) The Author(s) 2019 